\title{
VM Regimen
}

National Cancer Institute

\section{Source}

National Cancer Institute. VM Regimen. NCI Thesaurus. Code C10533.

A chemotherapy regimen consisting of vincristine and melphalan that may be used in combination with irradiation and combination chemotherapy in the treatment of pediatric metastatic rhabdomyosarcoma. 